\title{
AN INTERESTING CASE OF LEPRA REACTION
}

By Dr. Douglas E. Henry, B.SC., M.B.B.S. The Mission to Lepers, Chandkhuri Leprosy Hospital and Homes, P.O. Baital pur, via Bhatapara, M.P., India.

Reactions in leprosy are many and varied. At times some individuals present certain manifestations which are difficult to classify. The following case report is one such example. In this case the clinical picture resembled that of a Lucio-phenomenon. But on closely following the case this idea was over-ruled because, (1) up till now it has not been seen in Indian patients, and (2) the histopathology did not support this view.

However, one peculiarity in this case was the keratin plug in the centre of the lesions which differentiated it from other simple bursting nodules. At first this was not readily explained but on closely following the history and referring the literature it was more or less confirmed that the lesions were modified by the presence of keratosis blenorrhagica due to chronic gonorrhoeal infection.

\section{Case Report}

Name of the patient: Jwala Prasad Tiwari S/O Banwali Prasad Tiwari; age -35 years, sex-male, caste - Hindu Brahmin. Resident of village Maro (which is 7 miles from this institution). Former occupation - village teacher in a Primary School.

Family History: Married 15 years ago. Wife alive and well. Only one son, alive and well. None in the family had suffered from leprosy.

History of Contact: Lived for one year with a friend who was later diagnosed as suffering from leprosy.

Past History: In 1942 (20 years ago) the patient developed gonorrhoea which subsided after some treatment. In 1943 developed burning sensation in the extremities and eyes. He had frequent bouts of spermatorrhoea at nights and this cleared up after some time.

Present History: Started in 1953, when a diffuse hypopigmented patch resembling ringworm infection was seen on the right shoulder and another was seen on the back ( 5 years after the first patches were noticed) in 1958. The patient noticed some greasiness of the face and started having reddish nodules on the extremities. These nodules became painful and turned into blisters which later burst leaving small ulcer craters. These healed by treatment leaving whitish scars. The patient has been getting these attacks off and on and these have coincided with the recurrence of acute attacks of gonorrhoeal urethritis which seems to be resistant to penicillin therapy. Sometimes the 
nodules are numerous and they coalesce making the extremities very thick and very painful due to associated periostitis.

\section{Physical Examination}

$\mathrm{He}$ is a well developed male patient. The face looks greasy and there is uniform thickening of the skin of the face. The outer parts of both eyebrows have fallen out. There are two big subcutaneous nodules on right cheek and several small ones on both the cheeks. Heart, lungs and abdomen do not show any peculiarity. Extremities are covered with whitish scars and there are some subcutaneous nodules which are reddish and shiny. At other places there are ulcer craters formed by bursting nodules and some are covered with hard brownish crusts.

\section{Laboratory Findings}

$3+$ and $2+$ for lepra bacilli in skin smears.

Urethral smear - Extra cellular diplococci seen.

Stool - Hookworm ova present.

Kahn test -++++

Urine - Acidic, Sp.gr. 1010, albumen and sugar negative.

H.B. $-65 \%$ Total R. B.S. 35 millions cu.mm.

Smear of pus from the ulcer craters - Negative for diplococci. Tentative diagnosis - Reaction in leprosy, probably of Lucio type?

\section{Treatment}

The patient was treated for gonorrhoea, syphilis and hookworms and the haemoglobin became $80 \%$ with 4.14 millions of $\mathrm{RBC} / \mathrm{cu} . \mathrm{mm}$. Unfortunately this patient could not tolerate dapsone, sulphetrone and thiosemicarbazone. He got acute exacerbations with any of these drugs. But he could tolerate about $150 \mathrm{mgm}$. of INH per day, Etisul and Ciba-1906 were not tried because they were not available.

For reactions he was treated with PAT, Calcium Gluconate injections, APC, Irgapyrine and Butarin tablets, but relief was obtained only after using corticosteroids like Millicorten and Kenacort or Delta-efcortin.

\section{Progress}

In four years of hospitalisation the patient showed very slow but definite improvement. The general health is good and B.I. has fallen from 3.2 to 2 .

\section{Biopsies}

Two skin biopsies were taken $(a)$ one was taken from the forearm and (b) was taken from the leg. Each piece of skin included an ulcerated nodule. To make doubly sure about this diagnosis these were sent to two different experts. The following are the reports. 


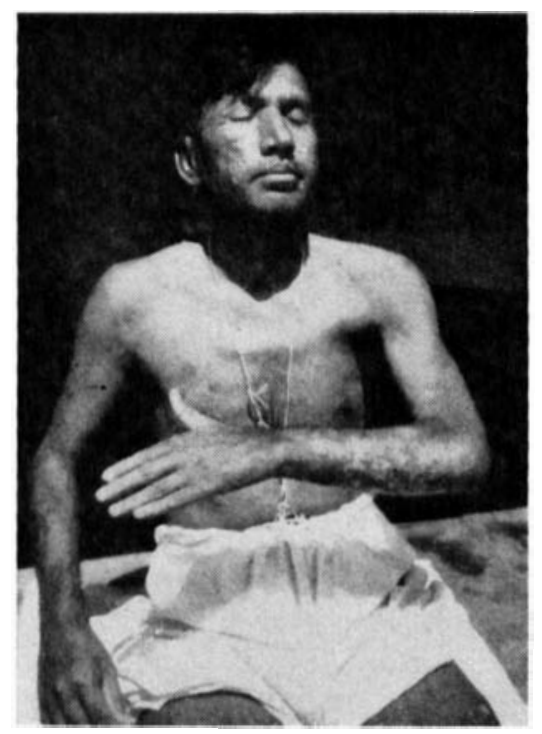

FIG. 1. Front view of the patient showing some loss of the outer aspects of the eyebrows, some subcutaneous modules on the face and some ulcer scars on the left fore-arm.

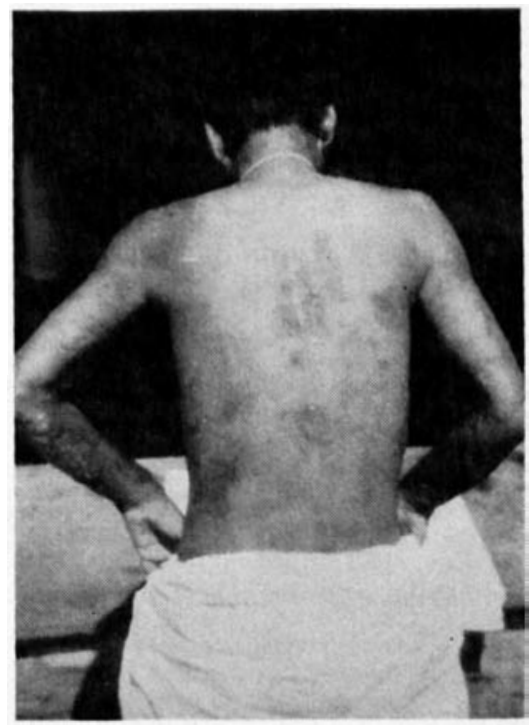

FIG. 2. Showing comparatively smaller number of modules on the back and more on the fore-arms. Earlobes are thickened but are not showing modulations. 


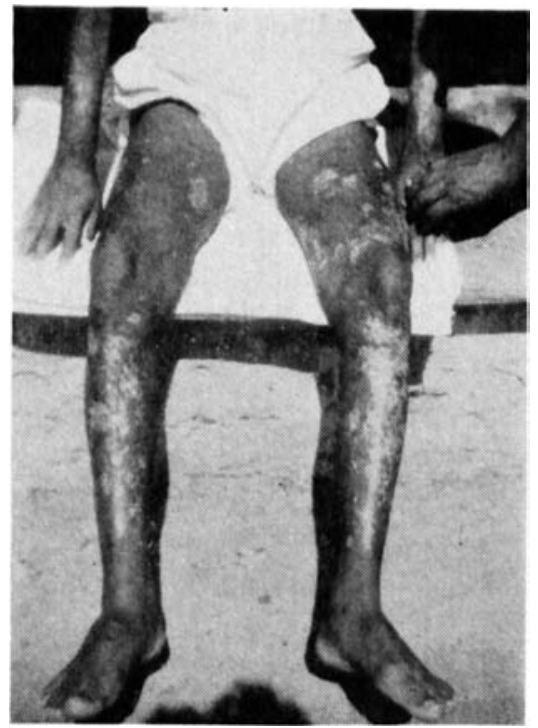

Fig. 3. Whitesh ulcer scars very well shown on the anterior aspect of the legs.

(a) Report by Dr. C. K. Job, M.D., Schieffelin Leprosy Research Sanatorium, Karigiri, South India.

'Macroscopic: A large piece of skin with a nodule in the middle. The nodule measures $1 \mathrm{~cm}$. across.

'Microscopic: This is an interesting case. Section shows epithelium showing pseudocpitheliomatous hyperplasis and a large keratin plug. There is a vessel in the corium which is completely obliterated. Acid fast stain shows a large number of lepra bacilli inside the macrophages.

'I had a similar case two years ago. This is a queer type of exacerbation of leprosy.

'Impression: Lepromatous nodule with Keratin Plug.'

(b) Report by Dr. George L. Fite, M.D., Chief Laboratory Branch, U.S. Public Health Service Hospital, Carville, Louisiana, U.S.A.

'The lesion is of course lepromatous in nature. It extends throughout the dermis and into the sub-cutaneous area and histologically is typically lepromatous with large number of small microcolonies. In some areas specially at the margins, there are good many plasma cells, which we are inclined to associate with the reactive states.

'In the central part of the lesion the epidermis is hyperkeratotic and there are masses of cells touching the epidermis containing very large numbers of bacilli. This appearance is that of lepromatous granulation tissue forming at the margins of healing lepromatous ulcers which have formed during a reactive episode. There has 
probably been some sloughing in this area and healing which is now essentially complete.

'It is my impression that this differs from the Lucio lesion, in which the necrosis stems from sort of vascularitis occurring in the lesion. It is my impression that more than one type of vascular process may occur in the Lucio phenomenon, either (1) Capillary thrombophlebitis, or (2) some allergic type of change with purpuric lesions or with additional endarteritis of small arterioles. Infection of the endothelium of the involved vessel is not essential to the Lucio lesion. The lesion in your case does not show the vascular lesion. Most (if not all) of the Lucio lesions are seen in infiltrative lesions in which the infilbrations are relatively thin and slender although numerous and containing numerous bacilli. In other words they occur dominantly in a somewhat different type of lepromatous leprosy in which there is no coalescence of the infiltrates to form nodules. The necrosis is essentially infarction of the skin areas due to loss of blood supply.

'We have seen the Lucio lesion only rarely other than of Mexican origin (from Sinaloa or Jalisco provinces), but they are very rare. However one patient now in the hospital (never been in Mexico, and of Caucasian parentage) shows the typical lepra honita infiltration form characteristically seen in Mexico.

'Thank you again for sending the lesion, and for the opportunity to study this interesting case.'

\section{Discussion}

This is a very interesting case because though clinically it resembled the Lucio form described in the literature yet on histopathological examination this was not confirmed.

An interesting thing noticed was the keratin plug found in the centre of the lesion. Its presence was not readily explained. But when we looked again at the history of the exacerbations of the symptoms with the recurrence of gonorrhoeal urethritis, it was presumed that chronicgonorrhoea had some part to play in this. In Sutton's, Diseases of the Skin (Mosbey, 11 th Edition, 1956) pp. 301-304, it is shown that gonorrhoeal keratosis blenorrhagica can present similar skin lesions. So it is presumed that in this particular case the lepra reactions were modified by gonorrhoea.

The second point of interest was the occurrence of this disease in a Hindu Brahmin in which this disease is not very common. Yet exposure to V.D. and to a patient in the form of a friend who was a leprosy patient might have given rise to the disease in this patient.

The third point of interest was the close resemblance of this form with that of Lucio phenomenon described by LATAPI and ZAMORA in 1948. Since then it has been thought that this form is confined to Mexico only. But it has been clearly brought out by the report from 
Carville that other than Mexican can also have this form of leprosy, and we should look for it.

\section{Summary}

1. A case of a queer and interesting type of lepra reaction in an Indian patient is described.

2. It is pointed out that the modification of skin lesion may be due to the coincidence of chronic gonorrhoeal infection.

3. It is presumed that the Lucio form may be found in races other than Mexican.

\section{Acknowledgments}

I wish to convey my sincere thanks to Dr. V. P. Das, Dr. P. J. Chandy and Dr. R. H. Thangaraj of Mission to Lepers who stimulated my interest in this case and gave encouragement and especially to Dr. C. K. Job of Karigiri and Dr. G. L. Fite of Carville for kindly examining the biopsy specimens and sending the path. reports.

\section{References}

1Cochrane, R. G. (1959). Leprosy in Theory and Practice, pp. 130-131.

2 Khanolkar, V. R. (1959). Leprosy in Theory and Practice. (Edited by Cochrane), p. 92.

3LAtapi, F and Zamora, A. C. The Spotted Leprosy of Lucio. Int. J. of Leprosy Oct.-Nov. 1948, 16, 421.

${ }^{4} \mathrm{Job}$, C. K. and Gault, G. W. Bullons type of Reaction in Lepros.'. Lep. Review' $1960,31,41-45$.

${ }^{5}$ SuTton Diseases of the Skin. (Mosby, 11 th ed., 1956). pp. 301-304. 